\title{
Performance Evaluation and Improvement among Salesmen in the Nigerian Fast Moving Consumer
} Goods Sector

\author{
Olutayo A. Olatunji $i^{1} \&$ Olawumi D. Awolusi ${ }^{2}$ \\ 1 University of Roehampton, London, UK \\ ${ }^{2}$ Kampala International University, Kampala, Uganda \\ olutayo.olatunji@roehampton-online.ac.uk, awolusi.olawumi@kiu.ac.ug
}

\begin{abstract}
This study examined the impact of systematic performance evaluation on performance improvement among salesmen in the Fast Moving Consumer Goods Sector in Nigeria. This is occasioned by the peculiar nature of the job of the salesman which requires that specific attention be paid to the mode of performance evaluation deployed for them and its impact on their productivity. Using Yamane formula, convenience sampling method was used to select 263 respondents from the sales team of PZ Cussons Nigeria PLC. Four hypotheses were subsequently tested using correlation test. Based on the analysis, the study found a significant influence of clear, specific and challenging goals on the performance of salesmen in the Fast Moving Consumer Goods sector in Nigeria. It was also deduced that there is no significant influence of detailed and timely feedback on the performance of salesmen in the Fast Moving Consumer Goods sector in Nigeria. Furthermore, the study also revealed a significant influence of employee reward and recognition, as well as, training and development on the performance of salesmen in the Fast Moving Consumer Goods sector in Nigeria. Based on the findings, the study recommended a clear, complete and inspiring job requirement of all salesmen so that the employee can continuously improve performance. Furthermore, feedback from appraisal and evaluation should also inspire, encourage and motivate salesmen without including any form of threat and fear of job security. Finally, Fast Moving Consumer Goods sector in Nigeria should embark on capacity development of human resources through training and mentoring. This study therefore contributes to limited studies on performance evaluation, as well as, validation of both the conceptual and theoretical postulations in the context of Fast Moving Consumer Goods sector in Nigeria.
\end{abstract}

Keywords: Systematic performance evaluation; performance improvement; Salesmen; Fast Moving Consumer Goods Sector; regression analysis; Nigeria.

\section{Introduction}

Achieving organizational objectives is highly impacted by the output of employees which continues to be improved. This thus requires that the performances of the individual employee are evaluated on a regular basis (Eze \& Awolusi, 2018; Gbande, 2016; Idowu, 2017). Performance evaluation, in the view of Arvey and Murphy (1998), can be described as 'performance appraisal', 'performance management' and 'performance assessment'. Idowu (2017) and Lunenburg (2011) also defined the concept of performance evaluation as "the process of identifying, evaluating and developing the work performance of the employee in the organization, so that organizational goals and objectives are effectively achieved while, at the same time, benefiting employees in terms of recognition, receiving feedback, and offering career guidance". A handful of works have been undertaken by different scholars on this subject beginning with Arvey \& Murphy in 1998 who used the annual review format to evaluate works that have been done in the past.

Akinbowale et al. (2013), using an approach similar to that of Arvey \& Murphy (1998), focused on how the improvement in the employee performance will help in the achievement of overall company objective. As such, performance evaluation should be embedded in the organization's HRM (Akinbowale et al., 2013). Obisi (2011) also attributed the lack of competitiveness of some organizations to the absence of a robust strategy on performance evaluation. Daoani (2012) however opined that performance evaluation could have either positive or negative influences on individual employee performances. This view seems to be the mid-way between the earlier two above. Based on gaps identified in literature, the above studies are however limited by their lack of attention to the place of employee in setting goals and knowing the expectations of supervisors. Also lacking is an examination of the diverse methods, as well as, the impact of available performance evaluation (Eze \& Awolusi, 2018; Gbande, 2016; Idowu, 2017). 
Other scholars however seemed to have addressed the gaps in the earlier work. Prominent among them is Shaout \& Yousif (2014) who opined that employees' level of engagement could be impacted by an effective performance evaluation in addition to improving their efficiency and effectiveness. The best way to identify the high performing employees in an organization is through regular evaluation of employees' performance and these are the ones who will always drive the continued attainment of organization's strategic objectives (Michlitsch, 2000). It is for this reason that Daoanis (2012) strongly recommended that there should be a diffusion of the organization's objective into the individuals' thereby ensuring that once all the employees' objectives are met, that of the organization is guaranteed. The shortcoming of this study lies in the failure to give a definite description of a 'high performing employee' when current realities shows that productivity is impacted by different soft and hard workplace factors. While agreeing that performance evaluation could negatively or positively impact performance of the employees, Daoanis (2012) who gathered his data via the quantitative and qualitative methodologies, concluded that there could possibly be other factors that will impact on employee performance (Oladejo \& Awolusi, 2018; Eze \& Awolusi, 2018). He thus identified the following gaps that could have an impact on the employee performance and these are: no appropriate rewards are given to best employees, appraisal system was not fully explained to employees, no feedback of results and employees do not participate in the formulation of evaluation tools (Daoanis, 2012).

If it truly wants to succeed and sustain its competitiveness. For this reason, suggested that the individual employee will be able to influence his career progression having determined what are his own personal strengths and weaknesses and working on them. PZ Cussons Nigeria PLC operates in the consumer packaged goods business in Nigeria, manufacturing and distributing such well-known brands. They operate in the Personal Care, Food and Nutrition, Home Care and Electrical categories where their brands such as Imperial Leather, Cussons Baby, Morning Fresh, Thermocool and Robb are either the market leader or a strong number two. With its vast distribution network spread across Nigeria, PZ Cussons Nigeria PLC employs different levels of sales men ensuring the availability of their products in all relevant retail outlets. With a 15\% growth in revenue in the operating year 2016 (PZ Cussons Annual Report, 2017), PZ Cussons Nigeria PLC is one of the few companies that were able to outperform the Nigeria economic trend in a year of fiscal recession. This thus makes it a veritable case study for a research that focuses on the performance evaluation and improvement, especially among their sales men who are in the frontline of their business activities. PZ Cussons Nigeria PLC has salesmen all over the country structured geographically along Lagos, West, Middle Belt and North. Each of these territories is headed by a Regional Sales Manager. The company in the last three years has been focusing on building capabilities among its sales team. The challenge however is that these efforts are not coming from identified gaps among the sales team.

Problem Statement: The nature of the work of the salesman is quiet peculiar and different from that of all other functions in an organization. This peculiarity requires that specific attention be paid to their performance evaluation processes and how it impacts their performances. Although many studies have been done concerning performance evaluation on employees generally, not many have been done specifically for salesmen, especially in Nigeria. This is perhaps the challenge PZ Cussons Nigeria PLC faced in that the same approach of developmental needs identification and trainings are been deployed to all employee cadres, including the sales team. With the numerous methods of performance evaluation available to the Human Resources Managers and the processes involved, it therefore becomes imperative that we examine the effect(s) of the different stages of the performance evaluation process on the performance of the salesmen. The organization therefore owes itself the duty of ensuring.

That performance evaluation contributes positively to employee performance. Studies in the past have employed single factor analysis to evaluate the performance of sales people. Such factors as functional knowledge and the influence of leadership styles have been used (Krishnan, Netemeyer, and Boles, 2002). This study thus helps to fill the gap in study by assessing the influence of performance evaluation of salesmen and conducting the study based on certain key variables such as clear, specific and challenging goals, detailed and timely feedback, employee reward and recognition, in addition to training and development on salesmen performance. Furthermore, past works had centered on worker motivation and staff evaluation in the government and corporate entity. This is coming rather from a not very good sales performance in 2016 when sales declined by $5 \%$ over 2015 . Numerous studies have examined the importance of performance evaluation in various ways to ensure improvement. 
In the performance of the organization (Champonda, 2014; Jabeen, 2011; Saeed and Shah, 2016; Singh and Rana, 2015; Sabeen, Mehboob, and Muhammad, A., 2008). Consequently, the main purpose of the study is to assess the impacts of performance evaluation of salesmen on their performances with a focus of the fast moving consumer goods sector in Nigeria. As such, examined how the different methods of performance evaluation affect the productivity of salesmen in the sector in focus. That notwithstanding, the specific objectives of this study are as follows:

- To assess the influence of clear, specific and challenging goals on the performance of salesmen in the Fast Moving Consumer Goods sector in Nigeria.

- To assess the influence of detailed and timely feedback on the performance of salesmen in the Fast Moving Consumer Goods sector in Nigeria.

- To assess the influence of employee reward and recognition on the performance of salesmen in the Fast Moving Consumer Goods sector in Nigeria.

- To assess the influence of training and development of salesmen on the performance of salesmen in the Fast Moving Consumer Goods sector in Nigeria.

Thus, there is no present examination that has concentrated on performance evaluation and improvement among salesmen in the fast moving consumer goods sector; this investigation subsequently tries to fill this learning hole by studying the impact of performance evaluation on salesmen performance in fast moving consumer goods sector concentrating on PZ CUSSION, Nigeria. Based on the specific objectives above and the background of the study, the following questions shall guide the study:

- Is there any significant influence of clear, specific and challenging goals on the performance of salesmen in the Fast Moving Consumer Goods sector in Nigeria?

- What is the influence of detailed and timely feedback on the performance of salesmen in the Fast Moving Consumer Goods sector in Nigeria?

- Is there any significance influence of employee reward and recognition on the performance of salesmen in the Fast Moving Consumer Goods sector in Nigeria?

- What is the influence of training and development of salesmen on the performance of salesmen in the Fast Moving Consumer Goods sector in Nigeria?

The unique and evolving nature of the job of a salesman makes it imperative that this type of study is conducted at this time of economic dynamism. This urgent importance of the need to understand of the motivating factors to the job of a salesman was also raised by Dubinsky (1998). For any organization to meet its objective and remain competitive in the long run, its crop of employees must be fully engaged and motivated. It is therefore important that the sum total goals and objectives of the individual employee become the overall goals of the organization and we find a way of regularly measuring and ensuring that the organization meets its objectives (Daoanis, 2012). An attempt to resolve these lingering controversies regarding the most effective way to measure and evaluate the salesmen's job and how this will impact their performances is what this current study is all about. It is hoped that this work will assist practitioners in sales and human resources to come up with the most effective and efficient methods of performance evaluation which will help the salesmen to improve their performances. In addition, scholars will also find the work useful in that it will afford them a new angle at viewing and evaluating the different theories of motivation, especially as it concerns salesmen in the fast moving consumer goods sector of the economy.

\section{Review of Related Literature}

Conceptual Review: Meeting the overall goals and objectives of an organization is dependent on how far each individual employee is able to meet their own goals. This is what underscores the importance of periodic individual performance evaluation, especially as it affects the overall organization goal achievement. Terms such as 'performance appraisal', 'performance management' and 'performance assessment' have been used by Arvey and Murphy (1998) to give definition to performance evaluation. It is the same process which has been defined as "the process of identifying, evaluating and developing the work performance of the employee in the organization, so that organizational goals and objectives are effectively achieved while, at the same time, benefiting employees in terms of recognition, receiving feedback, and offering career guidance" by Lunenburg (2011). In concord, Sanyal \& Biswas (2014) viewed performance evaluation as the process of 
measuring and controlling the performance of individual employee with a view to see how well it contributes to the organizational goal. This study is expected to deepen the understanding of HRM practitioners, sales managers and interested scholars in this critical subject of performance evaluation as it sits within performance management. This we will do by drawing the relationships between performance evaluation of salesmen and their on-the-job performance as these will be the two variables that will be examined in this work. And this will be specially focused on the fast moving consumer good, sector in Nigeria.

Figure 1: A Conceptual Framework of Salesmen Performance Evaluation

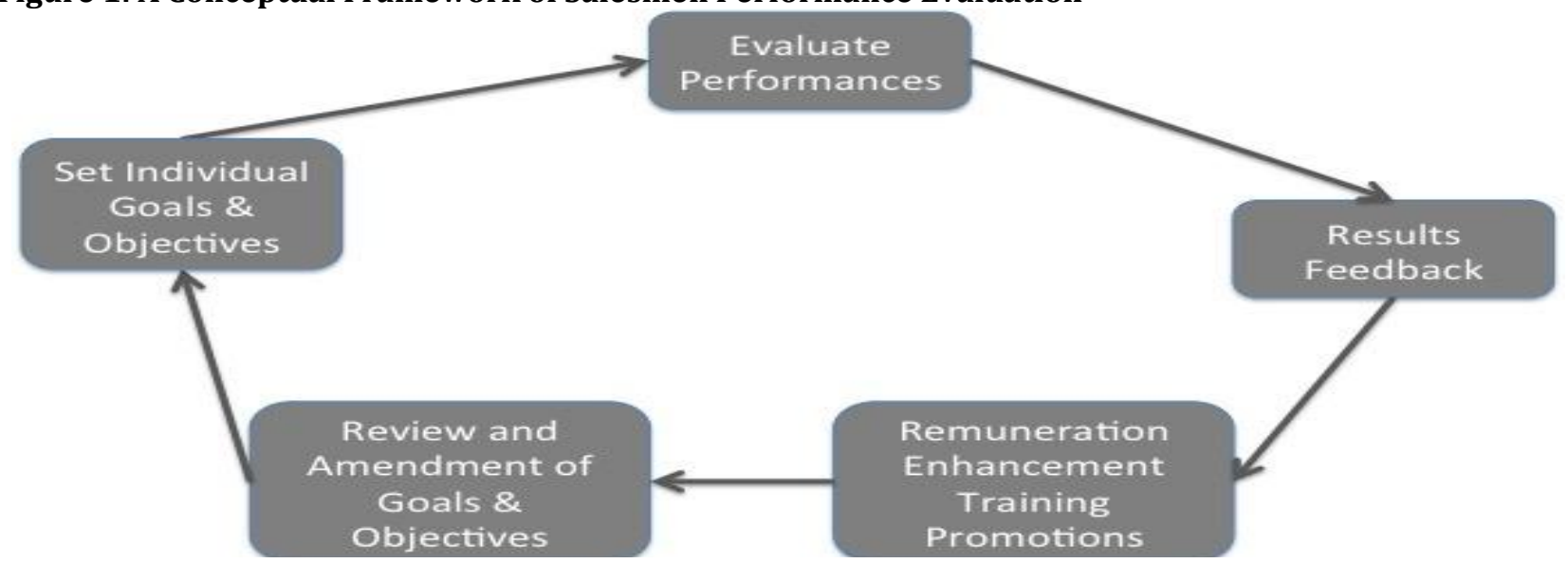

Adapted from Mabey’s Performance Management Cycle (Gbande, 2016)

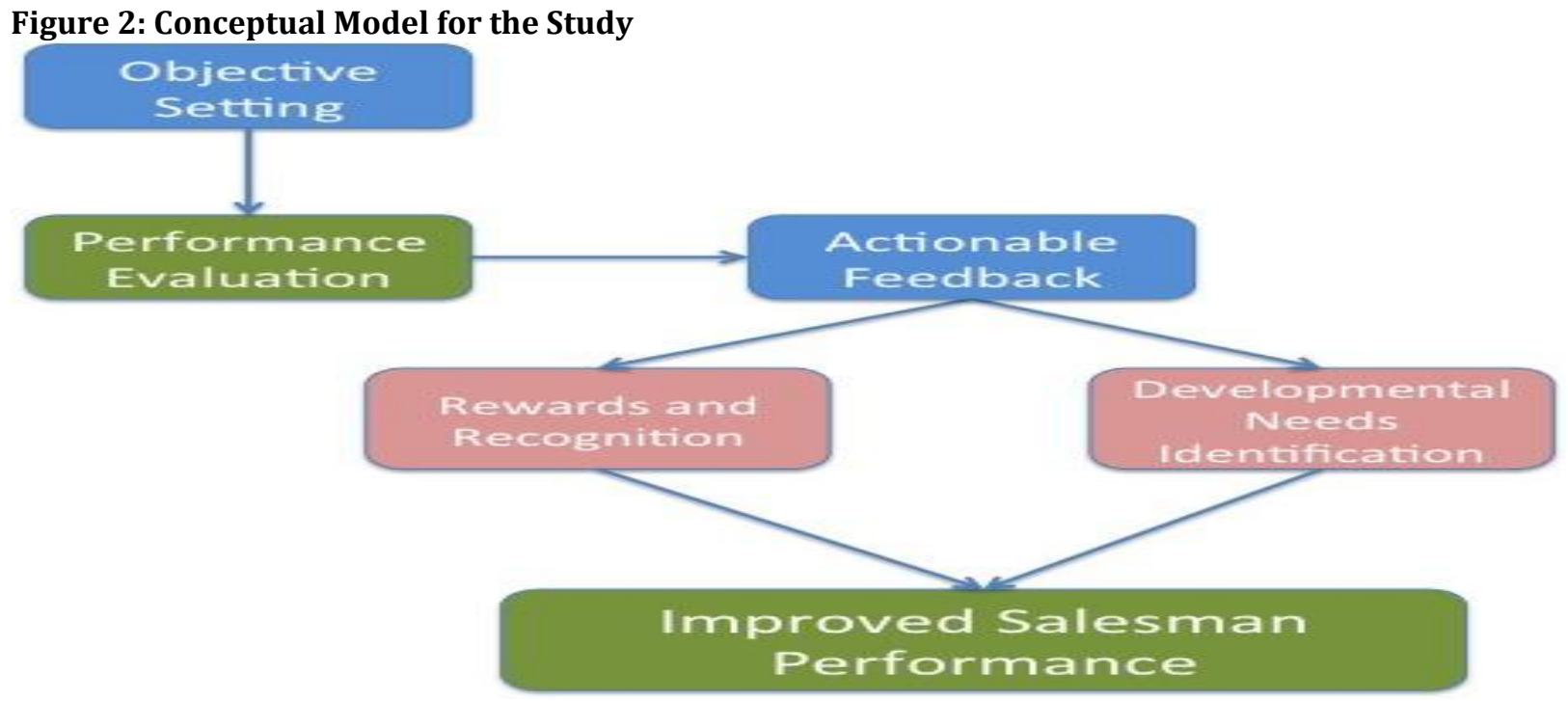

\section{Empirical Review and Development of Hypotheses}

Objective Setting: The effective attainment of organizational goals is perhaps the number one focus of any process of performance evaluation and it is the individual objectives that performances are measured against (Lunenburg, 2011). It therefore becomes imperative that critical attention is paid to this stage of the performance evaluation process. The renewed interest in performance management in the recent past has brought about a lot of focus on what Lunenburg (2011) and Gbande (2016) have referred to as "results, output, and goals". In this study, they concluded that when goals are made very clear, it aids improved performance for the employee. This stand is in concord with Goal Setting Theory propounded and expatiated by Latham \& Locke. The theory strongly recommends that for a sustained optimum employee performance, goals must be clear, specific and challenging (Gbande, 2016; Lunenburg, 2011). It therefore follows that if we 
desire an effective and efficient performance from salesmen, goals and objectives need to be made clear at the beginning of every period to be reviewed (Gbande, 2016; Lunenburg, 2011).

As such, salesmen will have a higher probability of achieving their objectives when it is stated very clearly without, any room for ambiguity. Rainey and Jung (2015) found, that when goals and objectives are made clear as opposed to being ambiguous, it leads to an improved performance. This is because ambiguity breeds uncertainty in a work environment thereby hindering the motivation for employees to perform at the optimum of their ability (Bronkhorst et al., 2015). The works here reviewed have focused largely on the developed economies and not particularly on the specific roles of salesmen. Although, it is expected that the case of salesmen in the Fast Moving Consumer Goods sector in Nigeria will be similar to these body of works. Hypothesis 1 (H1): Clear, specific and challenging goals will lead to improved performance among salesmen in the Fast Moving Consumer Goods sector in Nigeria.

Actionable Feedback: The objective of performance evaluation should be to "deliver more actionable feedback that produces greater learning, less defensiveness, and more appropriate action" (Gbande, 2016; Lunenburg, 2011: 67). Ideally, feedback should help the employee close the gap between current performance and the desired optimum performance. As such, feedback from the performance evaluation process will be deemed to have been successful if there is an improved performance from the employee that resulted from a new action or when a decision is made by the employee to consciously improve (McCarthy, 2017). However, for feedback to produce the desired results that is improved performance, Casas-Arce et al. (2015) believes it should be given infrequently, perhaps monthly, quarterly or annually and must be detailed. Conversely, when feedback becomes too frequent and less comprehensive, it loses its impact. Therefore, the timeliness as well as the objectively detailed nature of the feedback becomes quite imperative allowing the employee process the information (Gennaioli and Shleifer, 2010). A detailed feedback will allow for the identification of those activities or behaviors that are helpful for the achievement of objectives and needs to be reinforced. It will at the same time highlight those actions that are inimical to the achievement of the organization's objectives and need to be dropped (Casas-Arce et al., 2015).

Hypothesis 2 (H2): Detailed and timely feedback will lead to improved performance among salesmen in the Fast Moving Consumer Goods sector in Nigeria.

Rewards and Recognition: Higher productivity and improved performance has been associated with employees who are motivated and satisfied with their working conditions, including their wages (Caligiuri et al., 2010). This is just as reward and recognition could be either financial or non-financial in nature (DeCenzo \& Robbins, 2010). In other to ensure that rewards and recognition helps to drive organizational objective, it is important that this is tied to achievement of specified individual objectives. It is for this reason that Caligiuri et al. (2010) averred that clear criteria should be set for determining which employee to reward and this can be easily done through periodic performance evaluation. Since the goal of recognition is either to reinforce behaviors that support high level performance or to redirect or correct the underachiever, it becomes important that it be used objectively among the employees. As Tessema et al. (2013) argued that when not applied rightly, reward and recognition could become a demotivating factor and depress employee morale. It is also imperative to note that negative factors of motivation, such as the fear of loss of job, could serve same purpose of driving improved performance for the underachiever (Gbande, 2016; Lunenburg, 2011). On this basis, I propose the following hypothesis:

Hypothesis 3 (H3): Employee reward and recognition will lead to improved performance among salesmen in the Fast Moving Consumer Goods sector in Nigeria.

Developmental Needs Identification: Identification of the key areas of required improvement in the skill sets of a salesman is a pivotal element of the performance evaluation process (Saeed \& Asghar, 2012). Thus, performance evaluation will help to reveal the degree to which individual employee's knowledge, and skills match the job requirements (Gbande, 2016; Lunenburg, 2011). Other scholars however seemed to have addressed the gaps in the earlier work. Prominent among them is Shaout \& Yousif (2014) who opined that employees' level of engagement could be impacted by an effective performance evaluation in addition to improving their efficiency and effectiveness. When the skills needed to do an effective job is lacking in a salesman, developmental strategy can be put in place for such employee. It has been generally agreed that training will help the employees to have a better way of utilizing the resources of the organization, which results from improvement in their skill set (Blanchard \& James, 2007). Improved skills will generally lead to 
improved efficiency and higher productivity (Saeed \& Asghar, 2012). To this end, I propose the following hypothesis:

Hypothesis 4 (H4): Training and development of salesmen will lead to improved performance among salesmen in the Fast Moving Consumer Goods sector in Nigeria.

\section{Theoretical and Empirical Reviews of the Study}

Performance Evaluation: A handful of works have been undertaken by different scholars on this subject beginning with Arvey \& Murphy in 1998 who used the annual review format to evaluate works that have been, done in the past. In 2013, Akinbowale et al. using an approach similar to that of Arvey \& Murphy (1998), focused on how the improvement in the employee performance will help in the achievement of overall company objective. As such, performance evaluation should be embedded in the organization's HRM (Akinbowale et al., 2013). Obisi (2011) attributed the lack of competitiveness of some organizations to the absence of a robust strategy on performance evaluation. Daoani (2012) however opined that performance evaluation could have either positive or negative influences on individual employee performances. This view seems to be the mid-way between the earlier two above. These works are however limited by their lack of attention to the place of employee in setting goals and knowing what the expectations of their supervisors are. Also lacking is an examination of the diverse methods of performance evaluation that are available and what their impact could be. It is in view of the above that these authors undertake a study to compare those methods of performance evaluation that have been in use for a long time and those that have been recently introduced into the practice of HRM. From this comparative analysis came what they referred to as "an appropriate Fuzzy performance evaluation model" (Sahout \& Yousif, 2014, 976). Some the older methods considered includes the Ranking Method, Graphic Rating Scales, Critical Incident; Narrative Essays while Management by Objectives.

Behaviorally Anchored Rating Scale, Human Resource Accounting, Assessment Centers and the 360-Degree feedback method were the more recent ones. The analysis was in tabular form which enumerated the strengths and weaknesses of each method. While older methods identified by Sahout \& Yousif (2014) were simply focused on isolated tasks and functions which could be quiet mundane in approach, the more recent and modern methods tend to be more inclusive with employees being a part of defining their objectives (Sahout \& Yousif, 2014). The more pronounced drawback for the older methods is their subjective nature wherein the results of the evaluations are totally dependent on the whims of the supervisors (Dessler \& Gary 2011). And this drawback of subjectivity has been remedied by their transparency and the involvement of more people rather than only the supervisor (Sahout \& Yousif, 2014). The best way to identify the high performing employees in an organization is through regular evaluation of employees' performance and these are the ones who will always drive the continued attainment of organization's strategic objectives (Michlitsch, 2000). It is for this reason that Daoanis (2012) strongly recommended that there should be a diffusion of the organization's objective into the individuals' thereby ensuring that once all the employees' objectives are met, that of the organization is guaranteed. The shortcoming of this study lies in the failure to give a definite description of a 'high performing employee' when current realities shows that productivity is impacted by different soft and hard workplace factors. While agreeing that performance evaluation could negatively or positively impact performance of the employees.

Daoanis (2012) who gathered his data via the quantitative and qualitative methodologies concluded that there could possibly be other factors that will impact on employee performance. He thus identified the following gaps that could have an impact on the employee performance and these are: "no appropriate rewards are given to best employees, appraisal system was not fully explained to employees, no feedback of results and employees do not participate in the formulation of evaluation tools" (Daoanis, 2012: 29). The organization therefore owes itself the duty of ensuring that performance evaluation contributes positively to employee performance if it truly wants to succeed and sustain its competitiveness. For this reason, suggested that the individual employee will be able to influence his career progression having determined what are his own personal strengths and weaknesses and working on them. Having established the linkage between regular and objective performance evaluation and employee improved performance in the IT Industry in Indian, Sanyal \& Biswas (2014) could identify the reality of Herzberg's theory of motivation especially among the white collar workers who are mostly highly educated. In their opinion, the foundation for an effective 
performance evaluation is goal setting and a continuous monitoring of the performances of the employee. This finds a place in the proposed theoretical framework for this study that posits that for performance evaluation to have a positive impact on the salesmen, the basis has to be at the goal setting stage. In his own work, Obisi (2011) emphasized the importance of feedback and training need identification during the performance evaluation process.

With a focus on organizations in Nigeria, he opined that this process has not been quiet beneficial to these organizations due to the fact employees are usually oblivious of the areas of improvement required of them, thereby defeating the overall objective of performance evaluation (Idowu, 2017). This is the view shared by Ivancevich and Konopaske (2013) who suggested that for the performance evaluation process to help employees improve on their works, improvement areas need to be identified and the trainings put in place to facilitate improvements. These positions further validate the need to examine the effect of actionable feedbacks and developmental needs identification, as critical processes in the performance evaluation, on the performance of salesmen in Nigeria. This is what the theoretical framework for this study sets out to do, especially as it seems no such work, focusing on salesmen in the fast moving consumer goods sector of the Nigerian economy had been undertaken in the past.

Salesmen Performance: The current business environments is so competitive and constantly changing and therefore create the necessity for organizations to keep looking for new and better ways of ensuring that employees are constantly improving on their performances. This is more required for the sales team members who interface with the customers that needs to be delighted at all times (Awolusi \& Atiku, 2019; Baier et al., 2012). It therefore follows that any organization that wants to drive sustainable profitability will have to strive to improve the performance of its sales force (Baier et al., 2012 and Michlitsch, 2000). Madhani (2015) agrees with this view and averred that a motivated sales team will ensure that targets are regularly met. HRM practitioners and top management in organizations therefore need to begin to pay attention to both 'the results' and 'the processes' that produced the outcomes been evaluated if we truly want to integrate performance evaluation as a motivating factor. These two approaches have been elaborated by Madhani (2015) as "behavior based" and "outcome based" performance evaluations. This is the view shared by Damnjanovic and Krulj (2005) who opined that the salesman's performance is greatly influenced "external, personal (individual) and internal factors" and thus defined those as behavior based and results based evaluations.

Stretching this thought further, Damnjanovic and Krulj (2005) strived to understand the various factors that will have an impact on the evaluation of a salesman using the quantitative research methodology. It is through this study that they concluded that it is not enough to judge the performance of a salesman via sales result only. Using the regression-based capacity and productivity model, Baier et al. (2012: 42) concluded that it is expedient that a salesman be evaluated on the basis of "sales productivity, territory potential and years of experience". In order to therefore have the performance evaluation that will have a positive impact on its employee, the organization will have to find a balance between these two views. Salesmen will generally be on the look out to see what are the outcomes, if any, of the process of performance evaluation at the end of the business year; and this informed the opinion of Daoanis (2012) who averred that such career defining activities like promotions, salary review, trainings and other salesmen developmental programs should be based on performance evaluations. In Nigeria, this is not what is prevalent in lots of organization. Performance evaluations are principally used to measure how each employee or a unit fared versus the objectives that were set at the beginning of the year (Obisi 2011). Most organization employs such quantitative metrics as sales volume, sales value, number of customers, and growth over previous year.

As the basis of evaluating the job of their salesmen (Jolson et al., 1993). Munshi and Hanji (2014) however averred that there are other qualitative factors which help in the achievement of these quantitative results. They thus suggested that these qualitative metrics need to be evaluated just as we evaluate the quantitative factors. A robust analysis of already produced works on this subject was done by Munshi and Hanji (2014) who used the qualitative research methodology (Lapan, Quartaroli, and Riemer, 2012) in the collation of secondary data while also using the phenomenology research methodology (Gbande, 2016). As this present work will be looking at factors like "customer service/orientation, sales enhancement ability, product knowledge, presentation skill and team work", we can then make similar deductions as in the works of 
Munshi and Hanji (2014) which focused on retail sales people. On the other hand, the mixed method of research proposal (Creswell, 2003) which entails using structured questionnaires and interviews to gather quantitative and qualitative data respectively were used by Daoanis (2012) in the work titled "Performance Appraisal System: It's Implication to Employee Performance". It is from this study that Daoanis (2012) concluded that whatever method of performance evaluation employed by an organization can potentially impact performance of the employee, either in a positive or negative way.

Therefore, it becomes important that we have a deeper understanding and appreciation of the various performance, evaluation methodologies that are been used for salesmen in the fast moving consumer goods sector. We will also seek to know if these evaluations have any impact on the performance of the salesmen and to what extent if there are any. The Human Resources Management (HRM) has within its purview selected theories of performance improvement and management within which we will situate the impact and importance of performance evaluation. As such, we will conduct this study bearing in mind the Goal Setting Theory which was expounded by Edwin Locke in 1968 and the Expectancy Theory initiated by Victor Vroom in 1964 (Gbande, 2016; Lunenburg, 2011). Thus, building on the Goal Setting Theory, Lunenburg (2011) opined that employees will work assiduously to ensure that they achieve those goals which they were part of drawing up or setting for themselves and their units. This they do by following through with any improvement areas discovered during performance evaluation done within the period under review. As such, we see employees making adjustment in their operational tactics and possibly strategies to meet any shortfall. The Expectancy Theory on the other hand only focuses on different employees individually respond to different motivating factors without necessarily underlining any specific factor of motivation. Some of these theories are examined in detail bellow.

Organizational Theory - Resource Based View: Different scholars have at various times attributed different elements to have contributed to the improved performance of organizations. One of such is the Resource Based View as popularized by Lunenburg (2011). Proponents of this theory averred that there are some resources available to the firm which allows it to out-perform its competitors while there are those which enables to have long term competitiveness (Grant 1991; Wernerfelt 1984). Jarvenpaa and Leidner (1998) thus opined that the focus of the RBV is the correlation between the competitiveness of an organization and the resources it possesses and deploy effectively. It is in view of the aforementioned that Wade and Hulland (2014) affirmed that resources are those materials and skills that enables an organization spot opportunities in the market and take advantage of them. Apart from the controversy surrounding the most effective performance evaluation of the salesman's performance that prevailed in various literatures, it must be stated that a lot of works has been done on the subject matter but little consideration has been given to how performance evaluation impact salesmen performance. Findings of Rainey and Jung (2015) reveal that when goals and objectives are made clear as opposed to being ambiguous, it leads to an improved performance. Despite this finding, firms in the fast moving consumer goods sector are still found wanting in setting challenging, clear and inspiring goals that will increase performance. However, findings in this current study will fill this gap in literature and will hopefully create more gaps in research that future researchers will fill.

\section{Methodology}

Research Design, Strategy and Method of Data Gathering: Quite a number of studies have been done in the past on the subject of performance evaluation (Daoanis, 2012, Arvey and Murphy, 1998, Shaout and Yousif, 2014, Obisi, 2011, etc.) with focus on Western European countries. Scholars such as Akinbowale, Jinabhai and Lourens, (2013) on the other hand conducted similar studies within the Nigerian context, but specific to the banking sector. With these works done, the peculiarity of the salesman's job has yet to be looked into deeply. For this reason, this study will be focusing on the sales people in the fast moving consumer goods sector in Nigeria. We have therefore employed the use of the quantitative research methodology to test these hypotheses. We thus deployed what Vogts (1999) referred to as "a causalcomparative research" to understand the correlation between these two variables where performance evaluation has been classified as the independent or predictor variable and the performance of the salesman as the dependent variable. The quantitative research assigns numerical values to variables in other to examine their relationship (Oladejo \& Awolusi, 2018; Eze \& Awolusi, 2018). However, since data for this 
study were collected via structured questionnaires that were administered to randomly selected respondents; the findings were further transformed into a quantitative form so as to be able to carry out a further analysis. However, the researcher adopted descriptive quantitative research methodology. Since it helps to understand the behavior of the variable of interest in the study. In order to be able to attach numerical values to responses from this research, I have deployed questionnaires were planned using the Likert Scale format (Clason and Dormody, 1994).

Population of the Study: As this research has been limited to PZ Cussons Nigeria PLC, the sales team of the company thus becomes the population of this study. This is in line with Lunenburg (2011) who opined that a population for a research study must be defined by at least one common characteristic which will differentiated it from any other group (Oladejo \& Awolusi, 2018; Eze \& Awolusi, 2018). This is due to the affirmation made earlier that for an optimal evaluation of the work of a salesman, it has to be done with either 'result based' or 'behavior based' metrics (Damnjanovic and Krulj, 2005). As such, the sales team of the company is quiet distinct from all the other units of the company like finance, human resources, technical, supply chain or even the marketing teams. The composition of the sales team of PZ Cussons Nigeria PLC is defined as follows:

Table 1: Breakdown of the Sales Team of PZ Cussons Nigeria PLC

\begin{tabular}{lll}
\hline Designations & Number & $\mathbf{\%}$ \\
\hline Branch Managers & 7 & $1 \%$ \\
Regional Sales Managers & 31 & $4 \%$ \\
Field Sales Managers & 81 & $11 \%$ \\
Secondary Sales Force & 648 & $84 \%$ \\
Totals & 767 & $100 \%$ \\
\hline
\end{tabular}

In this case, the findings of this study will be applicable specifically to the sales team in this company as advanced by Govender and Abratt (2016).

Sampling Design and Sample Size: As the defined population for this study is too large, we will be constrained to select a sample which will be a true representative of the population. Selecting a sample from the population will allow us to observe and analyze our findings (Govender and Abratt, 2016). This is agreement with Lunenburg (2011) who argued that sampling is a way of selecting a part to be a representative of the whole. For the purpose of this study, the convenience sampling method has been used. This method has been described by Govender and Abratt (2016) as an arbitrary and unstructured way of choosing items from the whole population. This sampling method was chosen because of its relative effectiveness in terms of costs and time spent when compared to other methods of sampling. In addition, to determine the appropriate sample size to be used, the study adopted the sample size determination formula put forward by Yamane (1967, p.886). With a population of 767 sales people and a sampling error of 0.05, the sample thus becomes approximately 263 sales men and women. Consequently, convenience sampling method was used to select 263 respondents from the sales team of PZ Cussons Nigeria PLC. Table 2 depicts the sample size distribution of the questionnaire among the strata of the sales team.

Table 2: Sample Size Breakdown of the Sales Team of PZ Cussons Nigeria PLC

\begin{tabular}{llll}
\hline Designations & Number & $\mathbf{\%}$ & \# Respondents \\
\hline Branch Managers & 7 & $1 \%$ & 3 \\
Regional Sales Managers & 31 & $4 \%$ & 11 \\
Field Sales Managers & 81 & $11 \%$ & 28 \\
Secondary Sales Force & 648 & $84 \%$ & 221 \\
Totals & 767 & $100 \%$ & 263 \\
\hline
\end{tabular}

Data Analysis Strategy: As I have conducted an experimental quantitative research (Govender and Abratt, 2016), the data gathered have been made easy for the readers to have a quick understanding using tables, charts, graphs and other relevant non-textual elements in this work. With the different elements and variables considered, data obtained in this research have been tabulated. Descriptive analysis (EasterbySmith et al., 2012, pp.251-257) were then used to give more meaning to the tables and graphs that were 
presented. Since this study is considering the results of the salesman which are usually expressed in figures and his behavioral aspects, it became important that I make a distinction as well in the analysis. To this end, mean and standard deviation were used to analysis those results of the salesman that can be quantified and treated as a continuous variable. Furthermore, to test the hypotheses, correlation method was used. This method makes use of $\mathrm{P}$ values to assess the influence among variables. Thus decision would be made by comparing the level of significance with the $\mathrm{P}$ value. However, in other to achieve this, statistical software known as SPSS was used.

Reliability and Validity of the Research Instrument: For a study of this magnitude and importance to be adjudged empirically applicable, it must pass the test of reliability and validity (Awolusi, 2018; Awolusi, Mbonigaba, \& Tipoy, 2018; Mohajan, 2017). While validity refers to the accuracy and how stable the instruments used are, reliability refers to the consistency of the instrument to deliver same results when administered to different respondents, even at different times (Heale \& Twycross, 2015). As such, this study has employed the five-point Likert Scale (Sullivan and Anthony, 2013) to achieve the desired result. Reliability alludes to the consistency of discovery even after the questionnaire was administered (Gbande, 2016; Lunenburg, 2011). Cronbach's alpha coefficient was utilized to test the interior dependability of the survey. Validity of the survey instrument is a measure of what is expected to measure. The project supervisor and the specialists confirmed the instrument regarding content, construct and face validity, this process gave rise to a pilot test conducted (Gbande, 2016).

Critical Analysis of Methodology: The quantitative research methodology is famed for its ability to make a separation between the feelings and thoughts of the researcher from the results of the work (Awolusi, 2018; Awolusi et al., 2018). This ensures that the results obtained from using this methodology does not suffer from the subjectivity of the researcher, and this to a large extent. Lunenburg (2011) attests to the scientific nature of the quantitative research method in its analytics and conclusion drawings using an approach that is experimental. This then helps to cement the notion that it is possible to be objective, factual and less subjective even in management and social sciences (Awolusi, 2019; Awolusi \& Atiku, 2019; Yamane, 1967). Due to the use of mathematical models in analyzing data, the quantitative research methodology can validate assumptions with a measure of certainty (Williams, 2017). This methodology, which stems from the physical sciences will provide validating answers to questions as to 'how many' or 'how much' rather than merely 'how' (Sullivan and Anthony, 2013). Notwithstanding this possibility of this validity, it is important to "to have a sample that properly represents the population even if the precision is lower because of a small sample" (Easterby-Smith, 2012, Pg. 225). This underlies the critical importance of having the appropriate sample size from which we can generalize. Therefore, it becomes imperative that when the decision about the composition of the sample for the study is been decided, conscious effort should be made to balance representation and precision.

Possible Alternative Data Analysis Approach: The qualitative research methodology or the mixed methods of research are the other options that could have been employed for this study. In the words of Bogdan \& Biklen (1998), the qualitative research is an inductive means of research which helps us to make a better sense of "people construct meaning and to describe what those meaning are". The short coming of the qualitative research methodology is the fact it always involves a more limited number of respondents that could not be enough for a robust representation of the entire population. This makes its conclusions not having enough strong bases and this is in spite of its versatility (Easterby-Smith et al., 2012). The mixed method on the other hand is preferred for its ability to be used as a complementary approach to either of the qualitative or the quantitative methods and this coming from the possibility of mixing the two approaches and having the best of both (Gbande, 2016; Lunenburg, 2011). The challenge here however is the difficulty of mixing the data from these two distinct sources.

While we could agree that it is difficult to conclude that there is a better methodology when compared to the others, the different methods are able to complement each other with their respective strengths and weaknesses. In addition, when we rely solely on data obtained to test our hypothesis, we could run into a Type II error (Easterby-Smith et al., 2012). Bearing all the above in mind, we have endeavored to ensure that: we designed the questionnaire in such a way that the respondents will easily understand without compromising on the research objectives; we have also ensured that we provide explanation for each 
individual table and charts so that it will be easily understood. We could also be faced with the ethical issue of how to handle the identity of the respondents who could be nursing the fear of reprisals from senior management (Easterby-Smith et al., 2012). Respondents were not to submit personal details which could make it easy to know who responded; anonymity was highly safeguarded in order to protect the respondents.

\section{Results and Discussion of Findings}

Respondents' Demographic Characteristics: The respondents' distributions were analyzed using tables, percentage, distribution, graphs and charts. The Table 3 below shows the number of administered questionnaires as well as the number of those retrieved. It details the number of questionnaires administered to each of the designations and the number retrieved. As can be seen from the table, out of 263 items of questionnaires administered, 243 were retrieved which represents $92.4 \%$.

Table 3: Total Administered and Retrieved Questionnaires

\begin{tabular}{llll}
\hline Designations & Number & Number Administered & $\begin{array}{l}\text { Number } \\
\text { Retrieved }\end{array}$ \\
\hline Branch Managers & 7 & 7 & 4 \\
Regional Sales Managers & 31 & 26 & 20 \\
Field Sales Managers & 81 & 60 & 55 \\
Secondary Sales Force & 648 & 170 & 164 \\
Totals & 767 & 263 & 243 \\
\hline
\end{tabular}

Source: Research's Field Work

\section{Test of Hypotheses}

Test of Hypothesis One: $\mathbf{H}_{0}$ : There is no significant influence of clear, specific and challenging goals on the performance of salesmen in the Fast Moving Consumer Goods sector in Nigeria.

Table 4: Correlations for Hypothesis One

\begin{tabular}{llll}
\hline & & \multicolumn{1}{c}{$\begin{array}{c}\text { Clear, Specific } \\
\text { Challenging Goals }\end{array}$} & $\begin{array}{c}\text { Salesmen } \\
\text { Performance }\end{array}$ \\
\hline \multirow{2}{*}{ Clear, specific challenging goals } & Pearson Correlation & 1 & $.188^{* *}$ \\
& Sig. (2-tailed) & & .003 \\
& $\mathrm{~N}$ & 243 & 243 \\
Salesmen Performance & Pearson Correlation & $.188^{* *}$ & 1 \\
& Sig. (2-tailed) & .003 & \\
**. Correlation is significant at the 0.01 level (2-tailed). & 243 & 243 \\
\hline
\end{tabular}

Source: Output from SPSS

The Table 4 above shows the result of the correlation test. As can be observed from the table, there is a significant positive but weak relationship between clear, specific and challenging goals and salesmen performance with the Pearson correlation value of 0.188 and $p$-value of 0.003 . Since the $p$-value is lower than 0.05 , the null hypothesis that there is no significant influence of clear, specific and challenging goals on the performance of salesmen in the Fast Moving Consumer Goods sector in Nigeria is rejected. Thus it is concluded that there is a significant influence of clear, specific and challenging goals on the performance of salesmen in the Fast Moving Consumer Goods sector in Nigeria.

Test of Hypothesis Two: $\mathbf{H}_{0}$ : There is no significant influence of detailed and timely feedback on the performance of salesmen in the Fast Moving Consumer Goods sector in Nigeria. 
Table 5: Correlations for Hypothesis Two

\begin{tabular}{|c|c|c|c|c|}
\hline & & $\begin{array}{l}\text { Salesmen } \\
\text { Performance }\end{array}$ & $\begin{array}{ll}\text { Detailed } & \text { and } \\
\text { Feedback } & \\
\end{array}$ & Timely \\
\hline \multirow{3}{*}{ Salesmen Performance } & Pearson Correlation & 1 & .067 & \\
\hline & Sig. (2-tailed) & & .299 & \\
\hline & $\mathrm{N}$ & 243 & 243 & \\
\hline \multirow{3}{*}{ Detailed and timely feedback } & Pearson Correlation & .067 & 1 & \\
\hline & Sig. (2-tailed) & .299 & & \\
\hline & $\mathrm{N}$ & 243 & 243 & \\
\hline
\end{tabular}

Source: Output from SPSS

The Table 5 above shows the result of the correlation test. As can be observed from the table, there is no significant relationship between detailed and timely feedback and salesmen performance with the Pearson correlation value of 0.299 and $p$-value of 0.067 . Since the $p$-value is greater than 0.05 , the null hypothesis that there is no significant influence of detailed and timely feedback on the performance of salesmen in the Fast Moving Consumer Goods sector in Nigeria is refused to be rejected. Thus it is concluded that there is no significant influence of detailed and timely feedback on the performance of salesmen in the Fast Moving Consumer Goods sector in Nigeria.

Test of Hypothesis Three: $\mathbf{H}_{\mathbf{0}}$ : There is no significant influence of employee reward and recognition on the performance of salesmen in the Fast Moving Consumer Goods sector in Nigeria.

Table 6: Correlations for Hypothesis Three

\begin{tabular}{llll}
\hline & & $\begin{array}{l}\text { Salesmen } \\
\text { Performance }\end{array}$ & $\begin{array}{l}\text { Employee Reward } \\
\text { and Recognition }\end{array}$ \\
\hline \multirow{2}{*}{ Salesmen Performance } & Pearson Correlation & 1 & .764 \\
& Sig. (2-tailed) & & .002 \\
& $\mathrm{~N}$ & 243 & 243 \\
& Pearson Correlation & .764 & 1 \\
Employee Reward and Recognition & Sig. (2-tailed) & .002 & \\
& $\mathrm{~N}$ & 243 & 243 \\
\hline
\end{tabular}

Source: Output from SPSS

The Table 6 above shows the result of the correlation test. As can be observed from the table, there is a significant positive and strong relationship between employee reward and recognition on salesmen performance with the Pearson correlation value of 0.764 and p-value of 0.002 . Since the p-value is lower than 0.05 , the null hypothesis that there is no significant influence of employee reward and recognition on the performance of salesmen in the Fast Moving Consumer Goods sector in Nigeria is rejected. Thus it is concluded that there is a significant influence of employee reward and recognition on the performance of salesmen in the Fast Moving Consumer Goods sector in Nigeria.

Test of Hypothesis Four: $\mathbf{H}_{0}$ : There is no significant influence of training and development of salesmen on the performance of salesmen in the Fast Moving Consumer Goods sector in Nigeria. 
Table 7: Correlations for Hypothesis Four

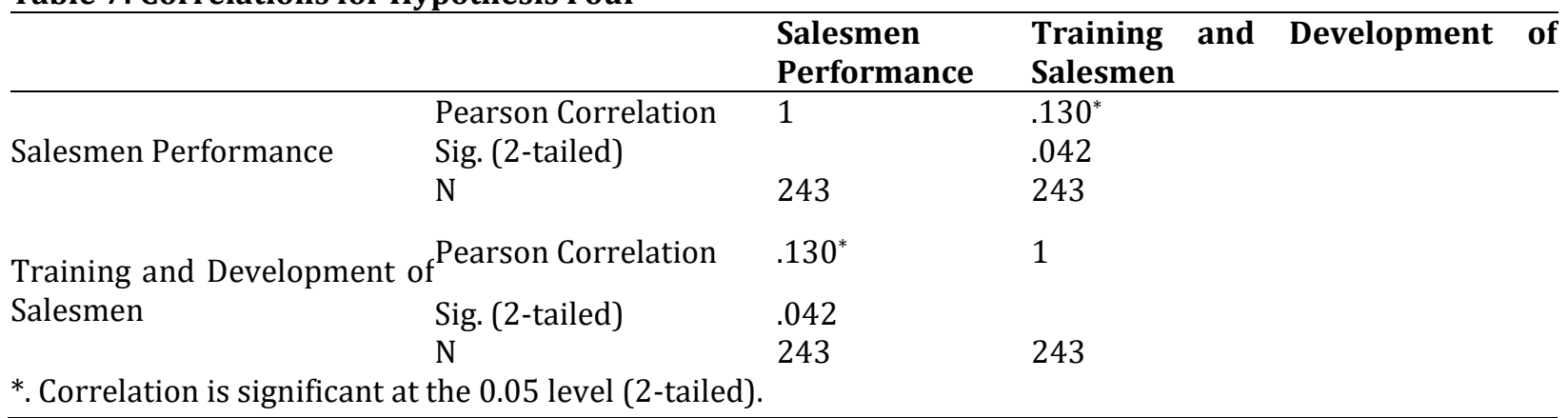

Source: Output from SPSS

The Table 7 above shows the result of the correlation test. As can be observed from the table, there is a significant positive but weak relationship between employee reward and recognition on salesmen performance with the Pearson correlation value of 0.130 and p-value of 0.042 . Since the p-value is lower than 0.05, the null hypothesis that there is no significant influence of training and development on the performance of salesmen in the Fast Moving Consumer Goods sector in Nigeria is rejected. Thus it is concluded that there is a significant influence of training and development on the performance of salesmen in the Fast Moving Consumer Goods sector in Nigeria.

Discussion of Findings: The study found that there is a significant influence of clear, specific and challenging goals on the performance of salesmen in the Fast Moving Consumer Goods sector in Nigeria. This implies that salesmen performance in most fast moving consumer goods prefer to work in an environment where sales task is clearly assigned with specific responsibility and non-interference by other units or persons. However, with a clear and challenging goal employee will perform optimally. Thus, salesmen will have a higher probability of achieving their objectives when it is stated very clearly without any room for ambiguity or vagueness. In addition, a clear, standardized and defined system, values and processes is important in developing the best policy, practice and helps in evaluating key steps in the salesmen performance of firms especially for fast moving consumer goods (Gbande, 2016; Lunenburg, 2011). Gbande (2016) revealed in their study that for a sustained optimum employee performance, goals must be clear, specific and challenging. Also a study by Lunenburg (2011) revealed that for an effective and efficient performance from salesmen, goals and objectives need to be made clear at the beginning of every period to be reviewed. Rainey and Jung (2015) found that when goals and objectives are made clear as opposed to being ambiguous, it leads to an improved performance. This current finding was consistent with the findings of these empirical above.

However, a study by Wotruba (1989) indicates that setting longer-range goals might be associated with higher performance, but quickly submitted that these results were mixed and not statistically significant. This is inconsistent with the finding of this study which found a statistically significant relationship between goal settings and performance of salesmen. Again, the study reveals that there is no significant influence of detailed and timely feedback on the performance of salesmen in the Fast Moving Consumer Goods sector in Nigeria. This finding implies that the result from appraisal feedback will not stimulate the performance of the salesmen. However, a situation where feedback is encouraging and inspiring, it results in improved performance, and will impact on the employee and thus resulting in a conscious improvement. We can therefore say that only positive feedback can improve performance. Casas-Arce et al. (2015) found in his study that when feedback becomes too frequent and less comprehensive, it loses its impact. This study is inconsistent with the study by Casas-Arce et al. (2015) which revealed that detailed feedback will allow for the identification of those activities or behaviors that are helpful for the achievement of objectives and needs to be reinforced. Furthermore, the study found that there is a significant influence of employee reward and recognition on the performance of salesmen in the Fast Moving Consumer Goods sector in Nigeria. Rewards and recognition are factors that influence the performance of salesmen.

Thus, it was agued by Mutia and Sikalieh (2013) that for firm to maximize salesmen they should combine both extrinsic and intrinsic reward strategies to achieve high performance firm overall. This finding is 
consistent with the findings of Caligiuri et al. (2010) which revealed that higher productivity and improved performance has been associated with employees who are motivated and satisfied with their working conditions, including their wages. A study by Umar (2010) revealed that a significant relationship exists between rewards and performance. Jimenez, Posthuma \& Campion, (2013) revealed in their study that salespeople can be motivated by different incentives. Their study further opined that rewards and compensation programs provide salesmen with the opportunity to earn rewards based on their performance. Gbande (2016) study's on reward system and productivity revealed that reward system is critical to the increase in the level of productivity of the employees. Also, a study by Lopez, Hopkins, and Raymond (2006) showed that compensation and reward systems are key methods of motivating the salespeople as well as influencing their behavior and performance. The results of these empirical studies are consistent with the findings of this study. Since the goal of recognition is to reinforce behaviors that support high level of performance, it is therefore important for the system of reward and recognition to be set in the right way so that the objective among the salesmen can be achieved (Boles et al., 2013).

Thus, this current study concluded that there is a significant influence of employee reward and recognition on the performance of salesmen in the Fast Moving Consumer Goods sector in Nigeria. Again, the study found that there is a significant influence of training and development on the performance of salesmen in the Fast Moving Consumer Goods sector in Nigeria. According to Nunvi (2006), organization training programs of salesmen is aimed at improving their current job performance and thus continuous training program will result in growth in the future of the organization. A well trained salesman in FMCG in Nigeria has a high tendency to perform better than other salesmen in the industry. Identification of key areas of improvement will aid the impact of training. Thus, training of salesmen will help minimize negligence and unlikely error that can cost the company (Mohajan, 2017). However, organizations must ensure that the appropriate skills are impacted on all salesmen according to their job requirement. Nassaz (2013) revealed in his study indicated that that training have a clear effect on the performance of employees. All the above stated empirical findings are consistent with the finding of this study.

\section{Conclusion, Recommendations and Implications}

This study was set to examine the impact of performance evaluation on performance improvement among salesmen in the fast moving consumer goods sector. To this end, the following were found based on the analysis: a significant influence of clear, specific and challenging goals on the performance of salesmen in the Fast Moving Consumer Goods sector in Nigeria; no significant influence of detailed and timely feedback on the performance of salesmen in the Fast Moving Consumer Goods sector in Nigeria; a significant influence of employee reward and recognition on the performance of salesmen in the Fast Moving Consumer Goods sector in Nigeria, as well as, a significant influence of training and development on the performance of salesmen in the Fast Moving Consumer Goods sector in Nigeria.

Conclusion: This study has attempted to examine the performance evaluation and improvement among salesmen in the fast moving consumer goods sector in Nigeria. To this end primary data was collected from the various respondent of the study PZ Cussons Nigeria PLC and was analyzed using the frequency table, hypothesis was tested using correlation test. Based on the analysis, the study found that there is a significant influence of clear, specific and challenging goals on the performance of salesmen in the Fast Moving Consumer Goods sector in Nigeria. Also, that there is a significant influence of employee reward and recognition on the performance of salesmen in the Fast Moving Consumer Goods sector in Nigeria. Furthermore, the study found that there is a significant influence of training and development on the performance of salesmen in the Fast Moving Consumer Goods sector in Nigeria. Also the finding regarding the effectiveness of goal-setting on the salesman performance can be used by FMCG to formulate relevant strategic planning policies that will have long lasting effect on the salesman performance as well as on the entire organization.

This study has contributed to knowledge in several ways. Conclusively, the study supported the notion that improving performance among salesmen is an important factor that increases the overall performance of the organization. Thus, in other to achieve this, organizations must ensure that a clear, specific and challenging goal is implemented on the job requirement of salesmen. Also, there is no significant influence of detailed and 
timely feedback on the performance of salesmen in the Fast Moving Consumer Goods sector in Nigeria. It is also important for the report from feedback should motivate salesmen as well as encourage them to improve performance. Thus, organization should create room for continuous improvement of salesmen performance. More importantly is the effect of reward and recognition. It has been observed that with either financial or non-financial reward, salesmen will be encouraged to perform at their fullest. Thus it is important for management to incorporate continuous recognition and reward to the job of any salesman. Training is another program that organization must adopt since the findings reveal a significant relationship between training and salesmen performance among Fast Moving Consumer Goods sector in Nigeria.

Recommendations: The recommendation of the study was based on certain findings made in the study; the following are recommended: The job requirement of any salesmen should be clear, complete and inspiring so that, the employee can give all it takes to achieve it and continuously improve performance. Also significant is the need to train each salesman on how to set goals relevant to their activities. Even though no significant relationship was found between timely feedback and salesman performance, however feedback that is positive can improve salesman performance. Hence, sales managers should provide feedback that is positive, not too frequent and comprehensive to their sales employees. Feedback from appraisal and evaluation should inspire, encourage and motivate salesmen without including any form of threat and fear of job security on it. Fast Moving Consumer Goods sector in Nigeria should setup a guideline of activities that motivate their salesmen in other to ensure outstanding performance, creative process and delivery. PZ Cussons should design incentives programs based on the performance of their sales employees. Incentive programs such as reward system and recognition can effectively enhance salesman performance. Fast Moving Consumer Goods sector in Nigeria should also embark on capacity development of human resources in the organization through the process of training and mentoring. Training and development is essential as it can enhance salesman performance.

Implications and Contributions to Knowledge: The findings of this research study are important for policy and practice for the concerned organizations and institutions. Organizations, especially those in the FMCG sectors will find the result of these findings useful in formulating policy for the purpose of improving practice. For instance, the finding regarding the effectiveness of reward system and recognition in improving salesman performance can be used to develop incentive programs that will improve practice and subsequently improve salesman performance. For instance the findings of this study have successfully filled the gap created in the literatures. Also this study has successfully carried out the study in FMCG sector in Nigeria. This marks a huge contribution to knowledge since this is arguably happening, perhaps for the first time and it reveals a substantial amount of findings which the academia as well as the practitioners can leverage on. The findings of this study will also serve as huge contribution to knowledge. However, this current study was delimited to Fast Moving Consumer Goods sector in Nigeria with special reference to PZ Cussons Nigeria PLC. Future study can be conducted on this same sector but with the consideration of more than one firm in the industry. Thus findings based on this can be used for proper generalization. Again, future study can adopt a different method of collecting data such as interview so that researcher can have close contact with the respondent thus information collected will be unbiased. Other methods of analysis could be used by future study such as regression etc.

Acknowledgement: This paper is an extracts from a Master of Business Administration thesis at the University of Roehampton, London. Prof. Olawumi .D. Awolusi was the supervisor of the study.

\section{References}

Akinbowale, M., Lourens, M. \& Jinabhai, D. (2013). Role of Performance Appraisal Policy and its effects on Employee Performance. European Journal of Business and Social Sciences, 2(7), 19-26.

Arvey, R. \& Murphy, K. (1998). Performance Evaluation in Work Settings. Annual Review of Psychology, 49(1), 141-168.

Awolusi, O. D. (2018). Policy and Non-Policy Factors: What Determines Foreign Direct Investments in Africa? Journal of Social and Development Sciences, 9(4), 49-61.

Awolusi, O. D., Mbonigaba, J. \& Tipoy, C. K. (2018). Mineral resources endowment and economic growth in Southern African countries, International Journal of Diplomacy and Economy, 4(1), 59-79. 
Awolusi, O. D. \& Atiku, O. S. (2019). Business Process Re-Engineering and Profitability in the Nigerian Oil and Gas Industry: The Mediating Influence of Operational Performance, Information Management and Business Review, 11(3), 13-26.

Awolusi, O. D. (2019). Human Capital Development and Economic Growth in BRICS Countries: Controlling for Country Differences, Journal of Economics and Behavioral Studies, 11(4), 1-17.

Baier, M., Carballo, J., Chang, A., Lu, Y., Mojsilovic, A., Richard, M., Singh, M., Squillante, M. \& Varshney, K. (2012). Sales-Force Performance Analytics and Optimization. IBM Journal of Research and Development, 56(6), 8:1-8:10.

Blanchard, P. N. \& James, W. T. (2007). Effective training (3rd Ed.). India: Dorling Kindersley.

Bogdan, R. \& Biklen, S. (1998). Qualitative Research for Education. 1st ed. Boston: Pearson/Allyn and Bacon, 38.

Boles, J., Donthu, N. \& Lohtia, R. (2013). Salesperson Evaluation Using Relative Performance Efficiency: The Application of Data Envelopment Analysis. Journal of Personal Selling \& Sales Management, 15(3), 3149.

Bronkhorst, B., Steijn, B. \& Vermeeren, B. (2015). Transformational Leadership, Goal Setting, and Work Motivation: The Case of a Dutch Municipality. Review of Public Personnel Administration, 35(1), 124145.

Caligiuri P., Lepak D. \& Bonache J. (2010). Global Dimensions of Human Resources Management: Managing the Global Workforce, Hoboken, NJ: John Wiley \& Sons, Inc.

Casas-Arce, P., Lourenno, S. \& Martinez-Jerez, F. (2015). The Performance Effect of Feedback Frequency and Detail: Evidence from a Field Experiment in Customer Satisfaction. Social Science Research Network Electronic Journal.

Champonda, N. (2014). Effect of performance appraisal on employee motivation. An MBA Project Report Submitted to the Chandaria School of Business: United States International University-Africa, Kenya.

Clason, D. \& Dormody, T. (1994). Analyzing Data Measured By Individual Likert-Type Items. Journal of Agricultural Education, 35(4), 31-35.

Creswell, J. (2003). Research design. 2nd ed. Thousand Oaks, Calif.: Sage Publications.

Daoanis, L. (2012). Performance Appraisal System: It's Implication to Employee Performance, International Journal of Economics and Management Sciences, 2(3), 55-62.

Damnjanovic, V. \& Krulj, D. (2005). Important Factors for Salesperson Evaluation. In: The 7th Balkan Conference on Operational Research. Constanta, Romania.

DeCenzo, D. A. \& Robbins S. P. (2010). Fundamentals of Human Resource Management (10th ed.), Hoboken, NJ: John Wiley \& Sons, Inc.

Dessler, L. \& Gary H. (2011). Human Resource Management. 10th Ed. New Jersey: Prentice Hall.

Dubinsky, A., Yammarino, F. \& Jolson, M. (1995). An examination of linkages between personal characteristics and dimensions of transformational leadership. Journal of Business and Psychology, 9(3), 315-335.

Easterby-Smith, M., Thorpe, R. \& Lowe, A. (2012). Management Research. 4th ed. London: Sage.

Eze, T. O. \& Awolusi, O. D. (2018). Effect of Critical Factors on Expatriate Assignment Performance in the Nigerian Oil and Gas Sector, Global Journal of Interdisciplinary Social Sciences, 7(2), 6-19.

Gbande, R. (2016). Effects of Reward System on Productivity in the Local Government System in Benue State. Journal of Economics and Sustainable Development, 7(22), 202-210.

Gennaioli, N. \& Shleifer, A. (2010). What Comes to Mind? The Quarterly Journal of Economics, 125(4), 1399 1433.

Govender, D. \& Abratt, R. (2016). Multiple Stakeholder Management and Corporate Reputation in South Africa. International Studies of Management \& Organization, 46(4), 235-246.

Grant, R. (1991). Knowledge and Organization in Managing Industrial Knowledge creation transfer and utilization, I. Nonaka and D. Teece, eds. London: Sage.

Heale, R. \& Twycross, A. (2015). Validity and Reliability in Quantitative Studies. Evidence-Based Nursing. [Online] Available at: https://ebn.bmj.com/content/early/2015/05/15/eb-2015-102129 [Accessed 26 Jul. 2018].

Idowu, A. (2017). Effectiveness of Performance Appraisal System and its Effect on Employee Motivation. Nile Journal of Business and Economics, 3(5), 3-13.

Ivancevich, J. \& Konopaske, R. (2013). Human resource management. New York, NY: McGraw-Hill Irwin.

Jabeen, M. (2011). Impact of Performance Appraisal on Employees Motivation. European Journal of Business Management, 3(4), 34-45. 
Jarvenpaa, S. L. \& Leidner, D. E. (1998). An Information Company in Mexico: Extending the Resource-Based View of the Firm to a Developing Country Context. Information Systems Research, 9(4), 342-361.

Jimenez, F. R., Posthuma, R. A. \& Campion, M. A. (2013). Effective incentive compensation for sales employees during tough economic times.

Jolson, M., Dubinsky, A., Yammarino, F. \& Comer, L. (1993). Transforming the Salesforce with Leadership. [online] www.sloanreview.mit.edu. Available at: http://sloanreview.mit.edu/article/transformingthe-salesforce-with-leadership/ [Accessed 19 Mar. 2018].

Kaario, K., Pennanen, R., Storbacka, K. \& Mäkinen, H. (2003). Selling Value: Maximize Growth By Helping Customers Succeed. Helsinki, WSOY 176p.

Krishnan, B. C., Netemeyer, R. G. \& Boles, J. S. (2002). Self-efficacy, competitiveness, and effort as antecedents of salesperson performance. The Journal of Personal Selling \& Sales Management, New York, 22(4), 285-295.

Lapan, S., Quartaroli, M. \& Riemer, F. (2012). Qualitative research. San Francisco: Jossey-Bass.

Lopez, T. B., Hopkins, C. D. \& Raymond, M. A. (2006). Reward preferences of salespeople: how do commissions rate? Journal of Personal Selling \& Sales Management, 25(4), 381-390.

Lunenburg, F. (2011). Goal-Setting Theory of Motivation. International Journal of Management, Business, and Administration, 15(1), 45-54.

Madhani, P. (2015). Managing Sales Performance: Behavior Versus Outcome Measures. Journal of Compensation \& Benefit Review, 47(2), 81-90.

McCarthy, J. (2017). Enhancing feedback in higher education: Students' attitudes towards online and in-class formative assessment feedback models. Active Learning in Higher Education, 18(2), 127-141.

Michlitsch, J. (2000). High-Performing, Loyal Employees: The Real Way to Implement Strategy. Strategy \& Leadership, 28(6), 28-33.

Mohajan, H. (2017). The Impact of Knowledge Management Models for the Development of Organizations. Journal of Environmental Treatment Techniques, 5(1), 12-33.

Munshi, M. \& Hanji, S. (2014). A Multidimensional Subjective Scale Development for Measuring Sales Performance of Retail Sales Personnel. IOSR Journal of Business and Management, 16(4), 39-47.

Mutua, P. \& Sikalieh, D. (2013). The influence of rewards and recognition on productivity levels among extension officers in the ministry of Agriculture in Kenya. Interdisciplinary Journal of Research in Business, 2(10), 31-39.

Nassaz, A. (2013). Effects of training on employee performance: Evidence from Uganda. Vaasan Ammattikorkeakoulu University of Applied Sciences International Business.

Nunvi, G. P. (2006). Business organization and management. $3^{\text {rd }}$ Edition.

Obisi, F. (2011). Training the Employee for Improved Performance: The Mediating Role of Employee Performance Appraisal. Texila International Journal of Management, 2(2), 111-118.

Oladejo, M. J. \& Awolusi, O. D. (2018). Effect of Work-Family Role Conflicts on Employees Commitment and Organisational Performance: A study of AKLAD Interlink concept, Nigeria, Global Journal of Commerce and Management Perspective, 7(2), 81-96.

Rainey, H. G. \& Jung, C. S. (2015). A Conceptual Framework for Analysis of Goal Ambiguity in Public Organizations. Journal of Public Administration Research and Theory, 25(1), 71-99.

Roman, S., Ruiz, S. \& Munuera, J. L. (2014). The effects of sales training on sales force activity. European Journal of Marketing, 36(11/12), 1344-1366.

Sabeen, Z., Mehboob, S. A. \& Muhammad, A. (2008). Perceived Fairness of and Satisfaction with Employee Performance Appraisal and Its Impact on Overall Job Satisfaction. The Business Review, Cambridge, $10(2), 453-467$.

Saeed, M. \& Asghar, M. (2012). Examining the Relationship between Training, Motivation and Employees Job Performance - The Moderating Role of Person Job Fit. Journal of Basic and Applied Scientific Research, 2(12), 12177-12183.

Saeed, S. \& Shah, M. (2016). Impact of performance appraisal on employee's motivation. Arabian Journal of Business and Management Review, 5(7), 34-45.

Sanyal, M. \& Biswas, S. (2014). Employee Motivation from Performance Appraisal Implications: Test of a Theory in the Software Industry in West Bengal (India). Procedia Economics and Finance, 11(1), 182196.

Shaout, A. \& Yousif, M. (2014). Performance Evaluation - Methods and Techniques Survey. International Journal of Computer and Information Technology, 3(5), 966-979. 


\section{Journal of Social and Development Sciences (ISSN 2221-1152)}

Vol. 10, No. 4, pp. 12-28, December 2019

Singh, P. \& Rana, S. (2015). Impact of Performance Appraisal on motivation, employee commitment and organizational effectiveness. Global Journal of multidisciplinary studies, 6(5), 342-354.

Stetler, K. \& Magnusson, M. (2014). Exploring the Tension between Clarity and Ambiguity in Goal Setting for Innovation. Creativity and Innovation Management, 24(2), 231-246.

Sullivan, G. M. \& Anthony, R. (2013). Analyzing and Interpreting Data from Likert-Type Scales. Journal of Graduate Medical Education, 5(4), 541-542.

Tessema, M., Ready, K. \& Embaye, A. (2013). The Effects of Employee Recognition, Pay, and Benefits on Job Satisfaction: Cross Country Evidence. Journal of Business and Economics, 4(1), 1-12.

Vogt, W. (1999). Dictionary of statistics and methodology: A nontechnical guide for the social sciences. 2nd ed. Thousand Oaks, CA: Sage Publications.

Wade, M. \& Hulland, J. (2004). The resource-based view and Information Systems Research: Review, Extension, and Suggestions for Future Research. MIS Quarterly, 28(1), 107-142.

Wernerfelt, B. (1984). A Resource-Based View of the Firm. Strategic Management Journal, 5(2), 171-180.

Williams, C. (2007). Research Methods. Journal of Business \& Economic Research, 5(3), 65-72.

Wotruba, T. R. (1989). The Effect of Goal-Setting on the Performance of Independent Sales Agents in Direct Selling. The Journal of Personal Selling and Sales Management, 9(1), 22-29.

Yamane, T. (1967). Statistics: An Introductory Analysis, 2nd Edition, New York: Harper and Row. 